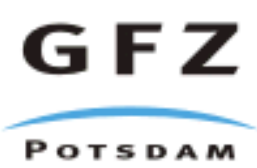

Originally published as:

Tibi, R., Wiens, D. A., Shiobara, H., Sugioka, H., Yuan, X. (2007): Double seismic discontinuities at the base of the mantle transition zone near the Mariana slab. - Geophysical Research Letters, 34, L16316

DOI: $10.1029 / 2007 G L 030527$. 
${ }_{3}$ Rigobert Tibi ${ }^{1}$, Douglas A. Wiens ${ }^{1}$, Hajime Shiobara ${ }^{2}$, Hiroko

\section{Double Seismic Discontinuities at the Base of the Mantle Transition Zone near the Mariana Slab}

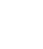

${ }^{1}$ Department of Earth and Planetary Sciences, Washington University,

St. Louis, Missouri, USA.

phone: 3149357965

fax: 3149357361

email: tibi@seismo.wustl.edu

${ }^{2}$ Earthquake Research Institute, University of Tokyo, Tokyo, Japan.

3 Institute for Frontier Research on Earth Evolution, Japan Agency for Marine-Earth Science Technology, Yokosuka, Japan

${ }^{4}$ GeoForschungsZentrum Potsdam, Potsdam, Germany

submitted to Geophysical Research Letters, April 28, 2007

revised July 27, 2007 
${ }_{16}$ Abstract

${ }_{17}$ We use $P$-to- $S$ converted phases from teleseimic data recorded at island and ocean 18 bottom stations in Mariana to investigate the upper mantle structure in the region. 19 We find evidence for double seismic discontinuities at the base of the transition zone 20 near the Mariana slab. A shallower discontinuity is imaged at depths of $\sim 650-715 \mathrm{~km}$ ${ }_{21}$ and a deeper interface lies at $\sim 740-770 \mathrm{~km}$ depth. The large lateral extent at near 22 constant depths for both features is consistent with horizontal interfaces rather than small-scale scatterers. The amplitude ratios of the seismic signals suggest that the shear velocity contrast across the two interfaces is comparable. These characteristics support the notion that the discontinuities are the results of phase transformations in olivine (ringwoodite to post-spinel) and non-olivine component (ilminite to perovskite), 27 respectively, for the pyrolite model of mantle composition. 


\section{Introduction}

The 660-km seismic discontinuity marking the bottom of the mantle transition zone is believed to result from an isochemical phase transition involving olivine, namely the dissociation of ringwoodite into perovskite plus magnesiowüstite [Ringwood, 1969]. However, mineral physics calculations and high-pressure experiments suggest that, depending upon the bulk mantle composition, transformations of non-olivine components such as the garnet system may lead to a complex structure of the 660-km discontinuity [Vacher et al., 1998; Hirose, 2002]. This is the case particularly along cold temperature profiles, similar to those expected in subduction zone environments. Under cold conditions, the transformation of garnet to ilminite, and the transition from ilminite to perovskite should cause two additional discontinuities near the base of the transition zone. These interfaces and the discontinuity induced by ringwoodite dissociation are expected to occur at distinct depths, causing multiple interfaces [Vacher et al., 1998]. Multiple seismic discontinuities near the base of the transition zone have been detected in thermally complex regions such as beneath southern California [Simmons and Gurrola, 2000] and northeast China, at the tip of the subducting Japan slab [Niu and Kawakatsu, 1996; Ai et al., 2003]. The 660-km discontinuity is routinely observed in global studies of long-period SS precursors [Shearer, 1993; Gossler and Kind, 1996]. Its non-detection on a global scale using precursors to long-period PP waves [Estabrook and Kind, 1996; Shearer and Flanagan, 1999] has recently been attributed to a complicated and highly variable structure, that shows single and double reflections, consistent with multiple phase transitions [Deuss et al., 2006].

We applied the $P$-wave receiver-function methodology [e.g., Vinnik, 1977] on teleseismic data recorded at island and ocean bottom stations in Mariana to investgate the upper mantle structure in the region and found evidence for double seismic discontinuties at the base of the transition zone around the Mariana slab. 


\section{Data and Analysis}

Data used in this study are seismograms from 315 earthquakes with epicentral distances from 30 to $95^{\circ}$, recorded at a temporary network in the Mariana region (Fig. 1). The network, which consists of 21 broadband island stations and 27 semi-broadband ocean bottom seismographs (OBS) operated from June 2003 to May 2004 [Tibi et al., 2006]. Also included are data recorded between 1991 and 2005 at the permanent station GUMO, located on the island of Guam.

The $P$-wave receiver-function technique applied in this study is well established and described in greater detail in Vinnik [1977] and Yuan et al. [1997]. Only key steps of the methodology are mentioned here. For land stations, the three-component seismograms are deconvolved to ground displacement and filtered at 2-30 sec. In order to isolate $P$-to- $S V$ converted phases, the seismograms are rotated to the LQT ray coordinate system. The earthquake source-time function is removed by deconvolving the $P$ energy on the $\mathrm{L}$ component from the rotated traces. The $\mathrm{Q}$ component contains $P$-to- $S V$ conversions. For the seafloor data, oceanic noise was successfully suppressed with an 8-30 sec bandpass filter. The orientations of the OBS's were determined using polarization angles obtained from airgun shots and large, well-located, distant events [Pozgay, pers. comm.]. The subsequent rotation and deconvolution procedures were performed the same way as for land data. We computed a total of 972 high-quality Q component receiver functions (RF's).

In order to enhance low-amplitude $P s$ converted phases from the upper mantle velocity discontinuities, we divided the study area into $1^{\circ} \times 2^{\circ}$-boxes and stacked moveoutcorrected RF's having piercing points at $660 \mathrm{~km}$ depth within the same box. Only stacks resulting from a minimum of 10 individual RF's were used to search for discontinuity conversions. The dimensions of the boxes were chosen so that there are sufficient RF's for each box, while insuring that the discontinuity phases within each box illuminate nearly the same structure. In a subduction zone, the most likely cause of major variations in the structure of the upper mantle discontinuities is the differ- 
ence in temperature between the subducting plate and the neighbouring mantle. The north-south orientation of the Mariana slab implies that these variations would occur primarily in the east-west direction. Hence, the dimension of the boxes in that direction were chosen to be only half the dimension in the north-south direction. For each box, we estimated the $95 \%$ confidence levels of the RF stack by performing bootstrap resampling [Efron and Tibshirani, 1991]. Only phases in the stack for which the lower confidence limit was clearly above zero were interpreted. This insures that random noise in the data are not misinterpreted as conversion from the discontinuities. Because of the difference in their frequency content (Fig. 2a and d), land and OBS recordings were stacked separately. However, for the few boxes with stacks both from land and OBS data, the inferred discontinuity depths were consistent among the two datasets within the estimated range of uncertainty.

\section{Results and Discussion}

Moveout-corrected RF's from land stations for one of the $1^{\circ} \times 2^{\circ}$-boxes is shown in Fig. 2a. The trace to the right is the stack of the RF's. In order to distinguish deep Ps conversions from multiples originating from shallow structures, RF's are stacked in slowness bins of $0.2 \mathrm{sec} / \mathrm{deg}$ to improve the signal to noise ratio, and subsequently sorted in order of increasing mean slowness. The procedure aligns $P s$ phases parallel to the slowness axis, while multiples become more inclined (Fig. 2b). The phases labeled '410', '660' and ' 750 ' can be correlated across nearly the entire slowness range at about 42,68 and $74 \mathrm{sec}$, respectively, suggesting that these phases are direct $P s$ conversions. In contrast, the delay time of the phase labeled 'mul.' decreases with increasing slowness from about $53 \mathrm{sec}$ to $48 \mathrm{sec}$, as expected for multiple reverberations (Fig. 2b). This interpretation is corroborated by the fact that this phase is aligned parallel to the slowness axis and enhanced in the stack, when the traces are moveoutcorrected for multiple reverberations PpPs (Fig. 2c). The phase, which is observed throughout the study area, is interpreted as $P p P s$ from an interface at about 150 $\mathrm{km}$ depth in the mantle wedge. The phases at about 42 and $68 \mathrm{sec}$ in Fig. 2a are 
conversions from the 410-km and 660-km discontinuity at depths of about 390 and 675 $\mathrm{km}$, respectively. We interpret the converted energy at $\sim 74 \mathrm{sec}$ as originating from an interface at about $740 \mathrm{~km}$ depth (hereinafter referred to as the $750-\mathrm{km}$ discontinuity). The low-frequency stack of the OBS RF's displayed in Fig. 2d shows basically similar features as the land data. In this case, however, the deep interface is observed at $\sim 760$ $\mathrm{km}$ depth, while conversion from the $660-\mathrm{km}$ discontinuity does not rise significantly above the background noise level.

Following Kind et al. [2002] we migrated the RF's obtained from land stations using a modified IASP91 velocity model [Kennett and Engdahl, 1991]. The modification included a crustal $P$ velocity model for the Mariana arc obtained from an active source study [Takahashi et al., 2007]. The crustal $S$ velocities were derived from that model using a $\mathrm{V}_{P} / \mathrm{V}_{S}$ of 1.73 . Fig. 3 shows an east-west section of the migrated traces along the $\mathrm{AB}$ profile indicated in Fig. 1. It includes RF's having piercing points at $660 \mathrm{~km}$ depth located within the latitude range of $15-17^{\circ} \mathrm{N}$. The $660-\mathrm{km}$ discontinuity is observed intermittently from longitude about 144.5 to $147.5^{\circ} \mathrm{E}$, and appears to be depressed to $\sim 705 \mathrm{~km}$ depth at $145.5^{\circ} \mathrm{E}$. The location of the depression coincides with the likely deep projection of the slab, suggesting that it is induced by the cold slab temperatures, as expected for the negative Clapeyron slope of the ringwoodite transition to post-spinel [Ito and Takahashi, 1989]. The lateral extent of only $\sim 100$ $\mathrm{km}$ for the depression suggests that in this region the Mariana slab penetrates the 660-km discontinuity with little or no advective thickening. Conversions from the interface at $\sim 750 \mathrm{~km}$ depth are observed between longitude about 145 and $148^{\circ} \mathrm{E}$. The intermittence of the observations is principally due to gaps in the interface sampling.

Results of the box-by-box stacking are summarized in Fig. 4. We estimate the uncertainty in discontinuity depths to be $\pm 10 \mathrm{~km}$, coming mainly from picking errors and uncertainties of the velocity model associated with the slab anomaly. The 660$\mathrm{km}$ discontinuity is observed in the depth range between about 650 and $715 \mathrm{~km}$, with the greatest depths occurring in the latitude range of $15-17^{\circ} \mathrm{N}$ within or near the Mariana slab (Fig. 4a). The inferred maximum depth for the $660-\mathrm{km}$ discontinuity is 
well within the range of 710-730 km obtained from a high-resolution study of $P 660 p$ and $S 660 p$ phases recorded at regional stations [Tibi et al., 2006]. The topography of the 750-km interface shown in Fig. 4b indicates a variation between about 740 and $775 \mathrm{~km}$ in depth. For most of the boxes in which we detected the $750-\mathrm{km}$ interface, we also observed the 660-km discontinuity (Fig. 4). This indicates the existence of two distinct discontinuities, demonstrating that the deeper interface is not the 660$\mathrm{km}$ discontinuity that has migrated to greater depth. Whereas the section in Fig. 3 shows double discontinuities between 145 and $148^{\circ} \mathrm{E}$, in Fig. 4 around $16^{\circ} \mathrm{N}$, double discontinuities are only seen between 146 and $147^{\circ} \mathrm{E}$. Variations in the structure of the 750-km interface across the relatively large stacking boxes in Fig. 4 are the most likely cause for this discrepancy.

Earlier studies have detected small-scale scatterers near the top of the lower mantle (at depths between 710 and $900 \mathrm{~km}$ ) around the Mariana slab [Krüger et al., 2001; Kaneshima, 2003]. The scatterers located within a high velocity anomaly [Bijwaard et al., 1998] have been interpreted as a piece of lithosphere or fragments of former oceanic crust subducted below the 660-km discontinuity [Krüger et al., 2001; Kaneshima, 2003]. The relatively large lateral extent of the $750-\mathrm{km}$ feature and its near constant depth throughout the study area (Fig. 3 and 4b) are clearly consistent with a horizontal interface rather than a series of small-scale scatterers, which would be randomly located. For each stack showing conversion both from the $660-\mathrm{km}$ and $750-\mathrm{km}$ discontinuity, we calculated the amplitude ratio between the two phases $\left(P_{750} s / P_{660} s\right)$. The amplidudes of $P$-to- $S$ conversion depend primarily on the magnitude of shear velocity contrast across the converting interface. Considering that $P_{750} s$ and $P_{660} s$ travel similar paths, and that differential attenuation due to the different conversion depths is negligible, the inferred average value of $1.01 \pm 0.22$ for $P_{750} s / P_{660} s$ indicates that the shear velocity contrast across the two discontinuities is comparable.

The most likely causes of deep, flat interfaces are isobaric phase transformations or compositional changes. Mineral physics calculations by Vacher et al. [1998] suggest that for a pyrolite model of mantle composition, at temperature conditions similar to 
those expected in subduction zones, garnet transforms to ilminite within the depth range of $608-664 \mathrm{~km}$. Under these conditions, the breakdown of ringwoodite takes place at depths of 690-693 km, while ilminite transforms to perovskite at 709-731 km depth. According to these authors, the garnet to ilminite transition occurs in a very broad pressure range, inducing a discontinuity that is rather weak. This may be the reason why we found no evidence for such interface. In contrast, both the breakdown of ringwoodite and the transformation of ilminite to perovskite are expected to cause relatively strong discontinuities of similar sharpnesses. Our observations appear to be consistent with these predictions. The occurrence of the $750-\mathrm{km}$ discontinuity seems to be restricted to regions surrounding the slab (Fig. 3 and $4 \mathrm{~b}$ ), assumed to be pyrolite mantle, further supporting our interpretation.

An alternative model for the observed $750-\mathrm{km}$ interface is that it may be the result of chemical layering associated with metasomatism in the uppermost lower mantle. In that model, the transport of elements by fluids released from descending slab may cause chemical layering or heterogeneity in terms of $\mathrm{Mg}_{2} \mathrm{O} / \mathrm{SiO}_{2}$ ratios [Ohtani et al., 2001]. As the Mariana slab is near-vertical, slab-expelled fluids could rise through the neighbouring mantle west as well as east of the slab, explaining the observation of the 750-km discontinuity both on the mantle wedge side and trenchward behind the slab (Fig. 3 and $4 \mathrm{~b}$ ).

Acknowledgments. Equipment for the land-based stations was provided by the PASSCAL program of IRIS. Lamont-Doherty provided the US OBS's. We are grateful to Megan Flanagan and an anonymous referee for their helpful review. This research was financially supported by NSF under grants OCE0001938 and EAR0310272. 


\section{References}

Ai, Y., T. Zheng, W. Zu, Y. He, and D. Dong (2003), A complex $660 \mathrm{~km}$ discontinuity beneath northeast China, Earth Planet. Sci. Lett., 212, 63-71.

Bijwaard, H., W. Spakman, and E. R. Engdahl (1998), Closing the gab between regional and global travel time tomography, J. Geophys. Res., 103, 30,055-30,078.

Deuss, A., S. A. T. Redfern, K. Chambers, and J. H. Woodhouse (2006), The nature of the 660-kilometer discontinuiy in Earth's mantle from global seismic observations of PP precursors, Science, 311, 198-201.

Efron, B., and R. Tibshirani (1991), Statistical data analysis in the computer age, Science, 253, 390-395.

Engdahl, E. R., R. van der Hilst, and R. Buland (1998), Global teleseismic earthquake relocation with improved travel times and procedures for depth determination, Bull. Seismol. Soc. Am., 88, 722-743.

Estabrook, C. H., and R. Kind (1996), The nature of the 660-kilometer upper-mantle seismic discontinuity from precursors to the $P P$ phase, Science, 274, 1179-1182.

Gossler, J., and R. Kind (1996), Seismic evidence for very deep roots of continents, Earth Planet. Sci. Lett., 138, 1-13.

Hirose, K. (2002), Phase transitions in pyrolitic mantle around 670-km depth: Implications for upwelling of plumes from the lower mantle, J. Geophys. Res., 10\%, 10.1029/2001JB000597. 
Ito, E., and E. Takahashi (1989), Postspinel transformations in the system $\mathrm{Mg}_{2} \mathrm{SiO}_{4^{-}}$ $\mathrm{Fe}_{2} \mathrm{SiO}_{4}$ and some geophysical implications, J. Geophys. Res., 94, 10,637-10,646.

Kaneshima, S. (2003), Small-scale heterogeneity at the top of the lower mantle around the Mariana slab, Earth Planet. Sci. Lett., 209, 85-101.

Kennett, B. L. N., and E. R. Engdahl (1991), Traveltimes for global earthquake location and phase identification, Geophys. J. Int., 105, 429-465.

Kind, R. et al. (2002), Seismic images of crust and upper mantle beneath Tibet: Evidence for Eurasian plate subduction, Science, 298, 1219-1221.

Krüger, F., M. Baumann, F. Scherbaum, and M. Weber (2001), Mid mantle scatterers near the Mariana slab detected with a double array method, Geophys. Res. Lett., 28, 667-670.

Niu, F., and H. Kawakatsu (1996), Complex structure of mantle discontinuities at the tip of the subducting slab beneath northeast China: A preliminary investigation of broadband receiver functions, J. Phys. Earth, 44, 701-711.

Ohtani, E., M. Toma, K. Litasov, T. Kubo, and A. Suzuki (2001), Stability of dense hydrous magnesium silicate phases and water storage capacity in the transition zone and lower mantle, Phys. Earth Planet. Inter., 124, 105-117.

Ringwood, A. E. (1969), Phase transformations in mantle, Earth Planet. Sci. Lett., 5, $401-412$.

Shearer, P. M. (1993), Global mapping of upper mantle reflectors from long-period SS precursors, Geophys. J. Int., 115, 878-904. 
249

Shearer, P. M., and M. P. Flanagan (1999), Seismic velocity and density jumps across the 410- and 660-kilometer discontinuities, Science, 285, 1545-1548.

Simmons, N. A., and H. Gurrola (2000), Multiple seismic discontinuities near the base of the transition zone in the Earth's mantle, Nature, 405, 559-562.

Takahashi, N. et al. (2007), Crustal structure and evolution of the Mariana intraoceanic island arc, Geology, 35, 203-206.

Tibi, R., D. A. Wiens, H. Shiobara, H. Sugioka, and P. J. Shore (2006), Depth of the $660-\mathrm{km}$ discontinuity near the Mariana slab from an array of ocean bottom seismographs, Geophys. Res. Lett., 33, L02313, doi:10.1029/2005GL024523.

Vacher, P., A. Mocquet, and C. Sotin (1998), Computations of seismic profiles from mineral physics: The importance of the non-olivine components for explaining the 660 km depth discontinuity, Phys. Earth Planet. Inter., 106, 275-298.

Vinnik, L. P. (1977), Detection of waves converted from $P$ to $S V$ in the mantle, Phys. Earth Planet. Inter., 15, 294-303.

Yuan, X., J. Ni, R. Kind, J. Mechie, and E. Sandvol (1997), Lithospheric and upper mantle structure of southern Tibet from a seismological passive source experiment, J. Geophys. Res., 102, 27,491-27,500. 


\section{Figure Captions}

Fig. 1. Bathymetric map of the Mariana region. Squares and triangles are locations of island stations and OBS sites, respectively. Hexagon indicates the station GUMO of the Global Seismic Network. Stars represent deep (depth >300 km) seismicity. The earthquakes include events re-located by Engdahl et al. [1998], and best located earthquakes that occurred during the operational period of the Mariana network. Raytheoretical Ps piercing points at $660 \mathrm{~km}$ depth for the calculated receiver functions are represented with crosses and dots for land and OBS data, respectively. The white line indicates the location of the profile displayed in Fig. 3. The inset at the upper-right corner shows the locations of the 315 events used in this study (circles), and the Mariana seismic network (triangle).

Fig. 2. (a) Moveout-corrected receicer functions. The traces were corrected for the directly converted phase $P s$ and a reference slowness of $6.4 \mathrm{sec} / \mathrm{deg}$ using a modified IASP91 velocity model [Kennett and Engdahl, 1991]. Receiver functions are from island stations, and include data having $P s$ piercing points at $660 \mathrm{~km}$ depth located within the box at $11-13^{\circ} \mathrm{N}$ and $146-147^{\circ} \mathrm{E}$. Delay time is relative to the direct $P$ wave. The thin horizontal lines indicate the predicted arrival times for $P$-to- $S$ conversions at 410 and $660 \mathrm{~km}$ depth. The trace to the right is the stack of the receiver functions for this box. The gray areas in the stack indicate robust conversions for which the lower $95 \%$ confidence limit is above zero. Conversions from the 410, 660-km, and $750-\mathrm{km}$ discontinuities are marked with arrows. Multiples from an interface at about $150 \mathrm{~km}$ depth are labeled by 'mul.' (see text). (b) Slowness-stacked receiver functions. The waveforms shown in (a) have been averaged over slowness bins of $0.2 \mathrm{sec} / \mathrm{deg}$. The slowness range of 7-9 sec/deg corresponds to the range of epicentral distances of about $31-58^{\circ}$ for the events that sample the box. Horizontal dotted lines at about 42,68 and $74 \mathrm{sec}$ delay time indicate conversions from the 410, 660 and 750-km discontinuities, respectively. White dots mark multiples from the $150-\mathrm{km}$ interface. (c) The same as in 
(b) except that the traces were moveout-corrected for multiple reverberations $P p P s$.

(d) The same as in (a) for the OBS data and the box at $15-17^{\circ} \mathrm{N}$ and $142-143^{\circ} \mathrm{E}$.

Fig. 3. East-west profile of migrated receiver function data. The location of the profile is shown in Fig. 1. Data are from island stations, and include receiver functions with $P s$ piercing points at $660 \mathrm{~km}$ depth located within the latitude range of $15-17^{\circ} \mathrm{N}$. Red (blue) indicates velocity increase (decrease) downward. The black thick arrow indicates the position of the slab, as defined by seismicity (dots). The thin horizontal line indicates the depth of $660 \mathrm{~km}$. Conversions from the $660-\mathrm{km}$ discontinuity and 750-km interface are marked with black and green line segments, respectively. Note the small-scale depression between 145 and $146^{\circ} \mathrm{E}$ for the $660-\mathrm{km}$ discontinuity.

Fig. 4. Maps of the discontinuity depth. Crosses and dots indicate Ps piercing points at $660 \mathrm{~km}$ depth for land and OBS data, respectively. Circles represent deep (depth $>300 \mathrm{~km}$ ) seismicity. The discontinuity depth for each $1^{\circ} \times 2^{\circ}$-box was estimated from the stack obtained after summation of the RF's having $P s$ piercing points at 660 $\mathrm{km}$ depth located within the box. Boxes with weak conversions from the discontinuities or null observations are indicated in white. (a) Depths of the 660-km discontinuity. (b) The same as in (a) for the $750-\mathrm{km}$ discontinuity. 


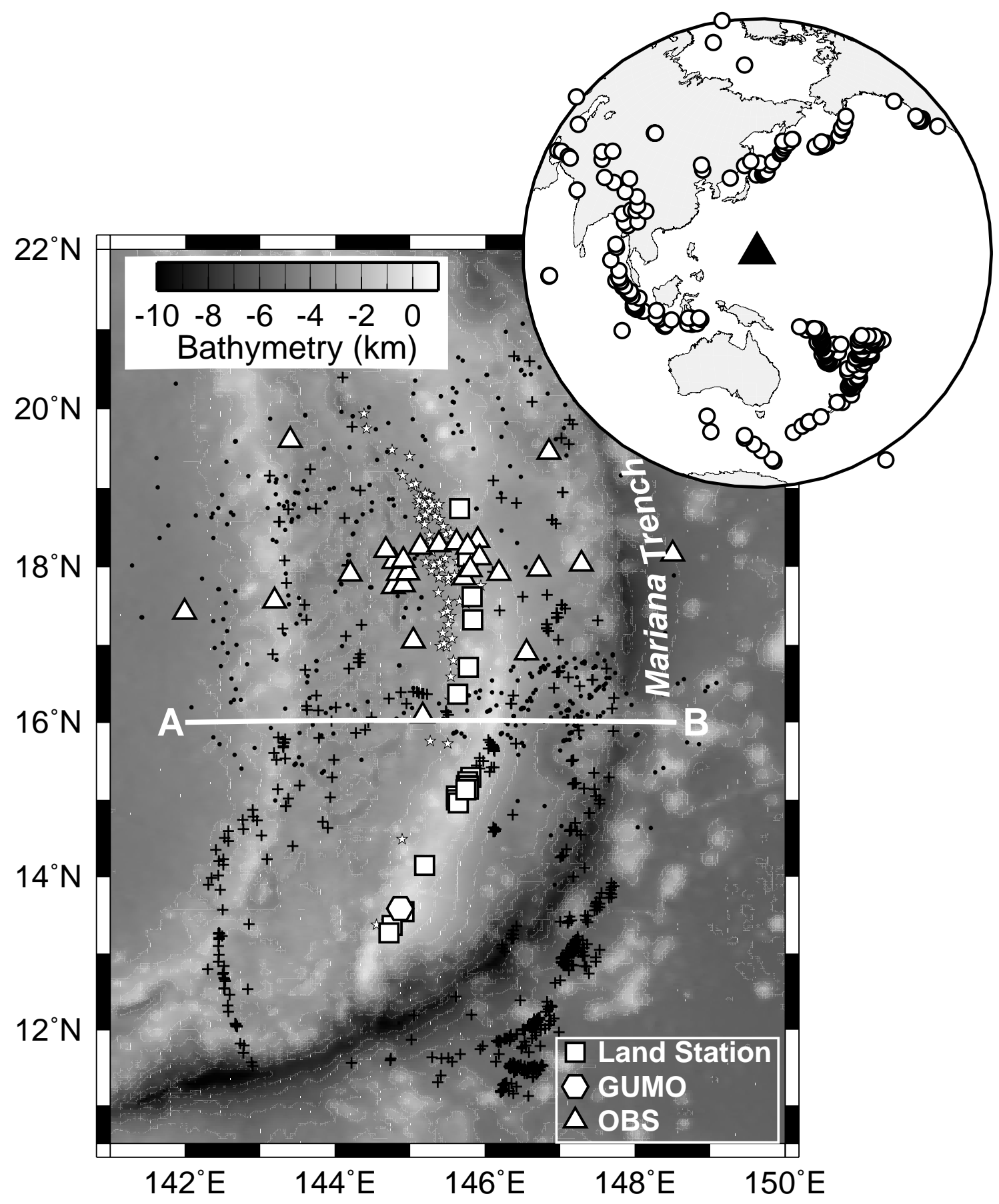

Figure 1: Tibi et al. 

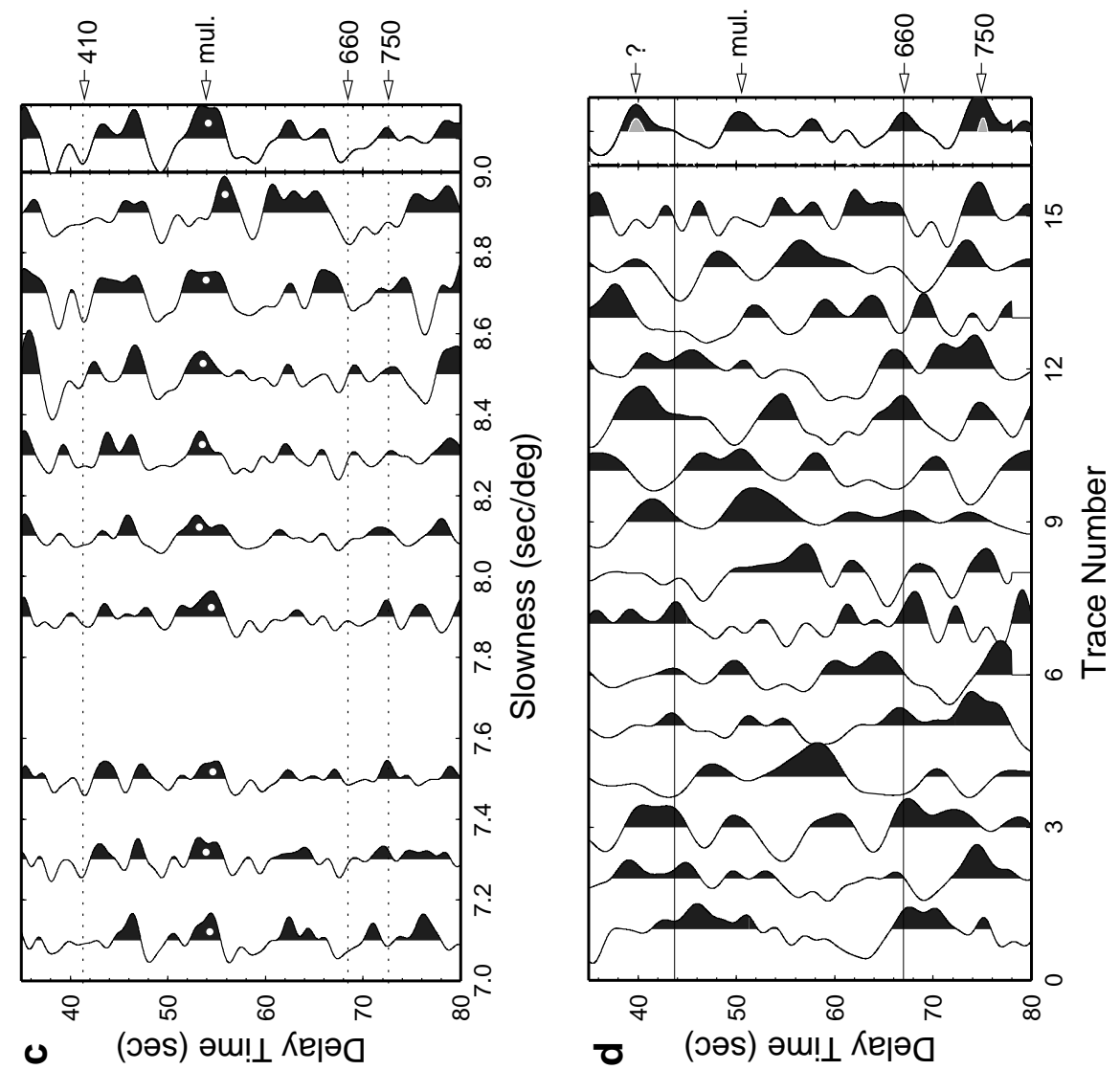

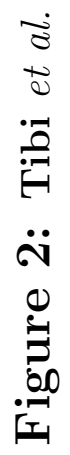
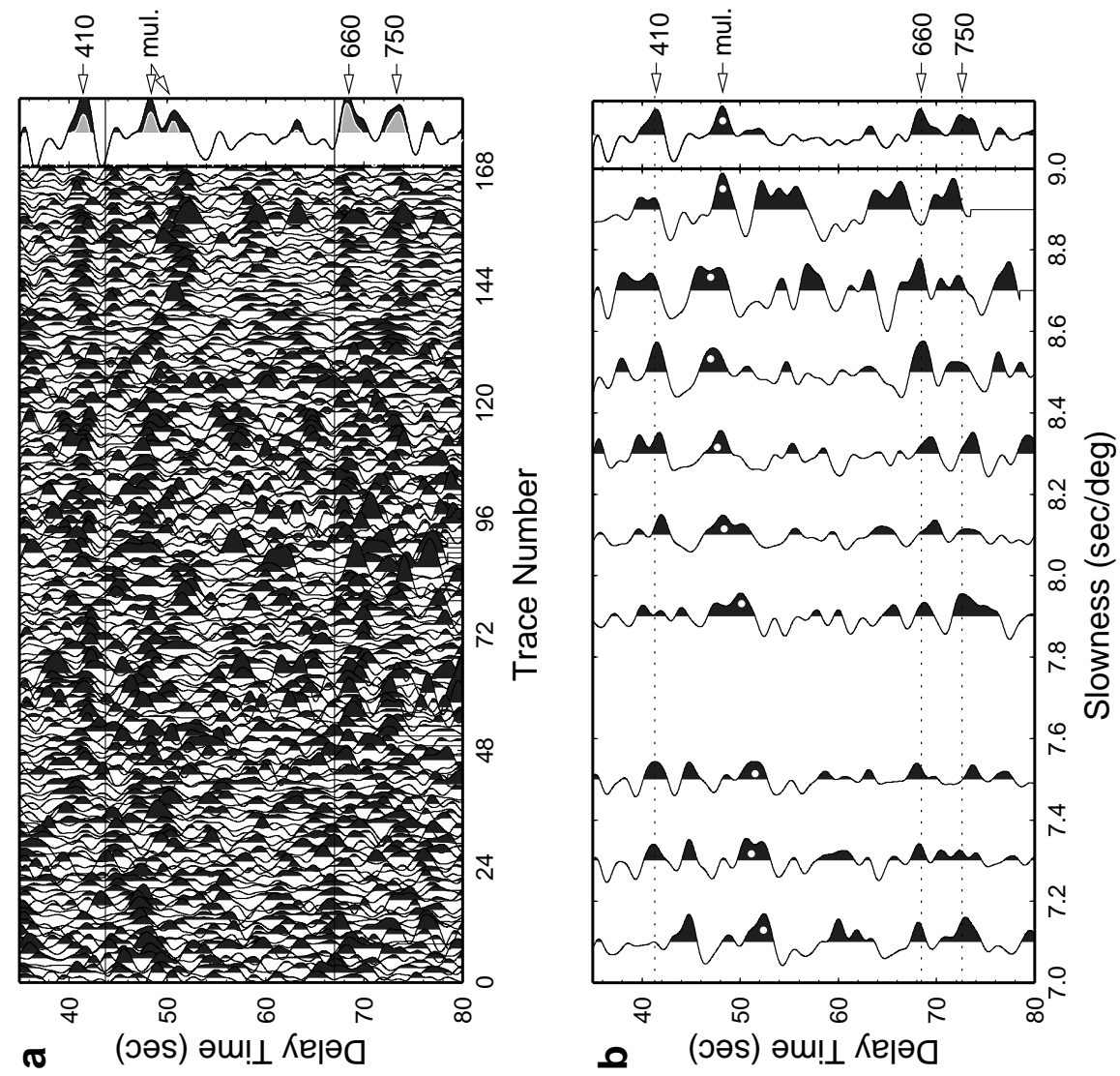


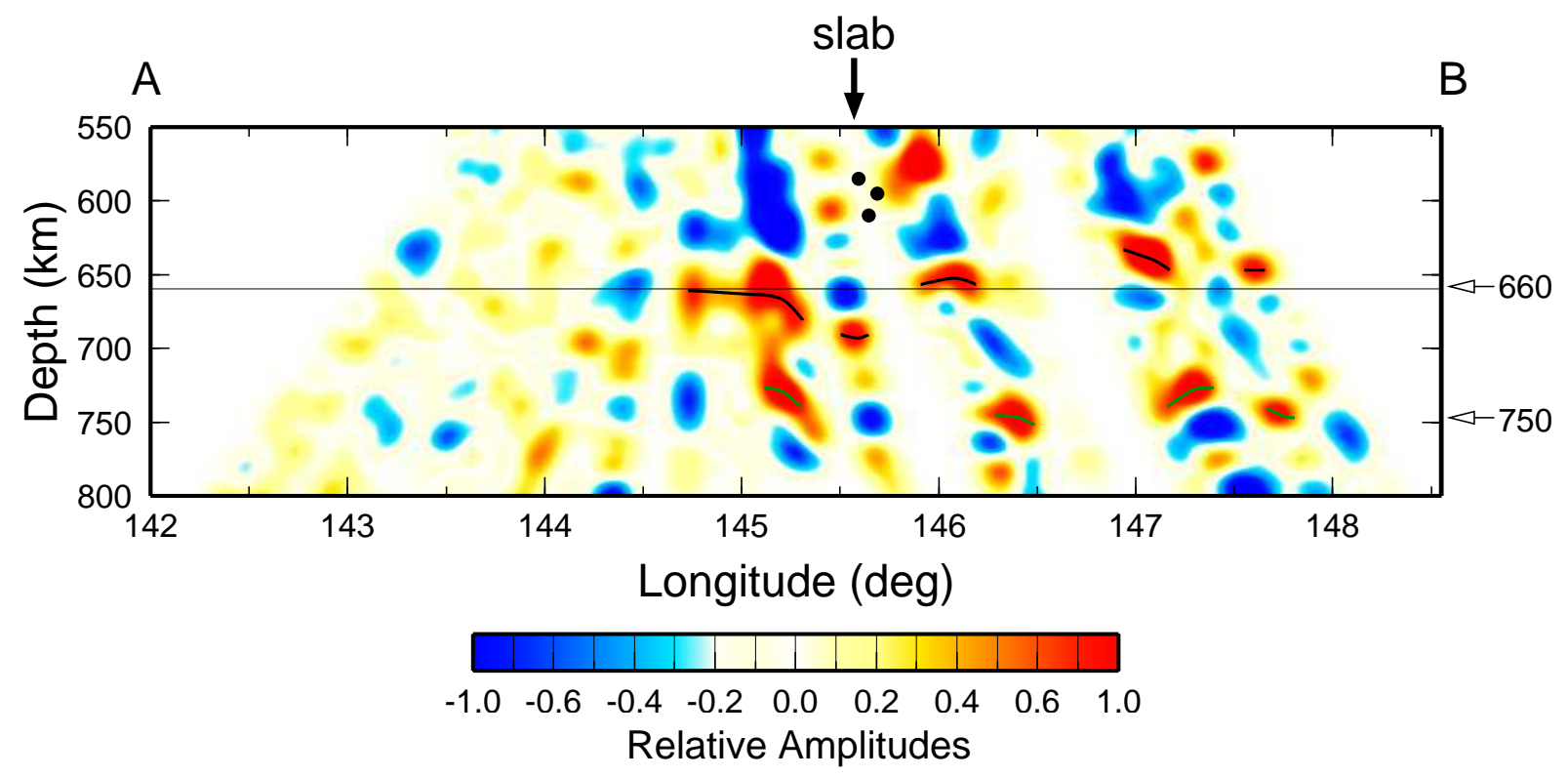

Figure 3: Tibi et al. 


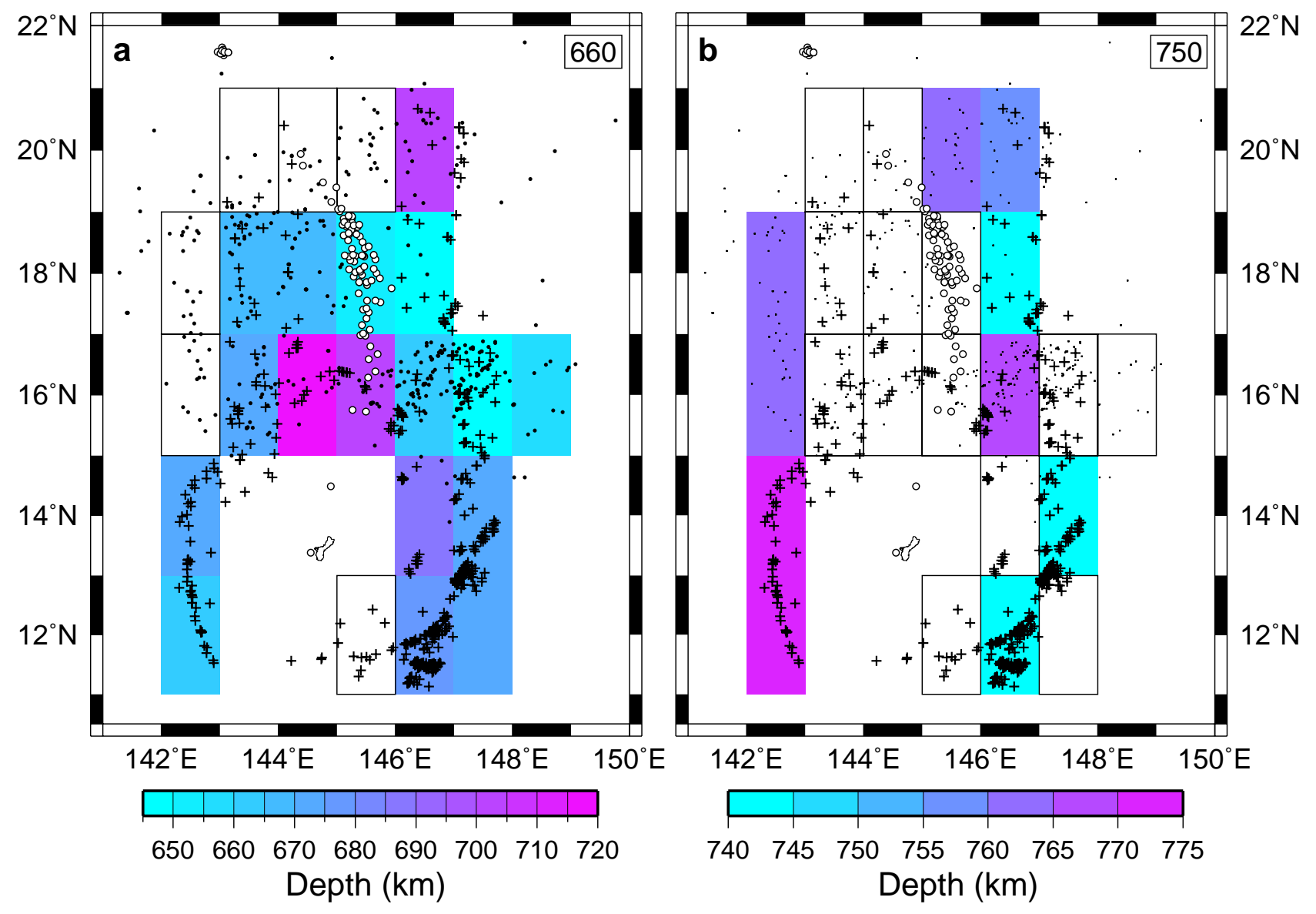

Figure 4: Tibi et al. 